\title{
Neuro-genetic approach for optimization of the water flowrates distribution on a hydrogen sulphide cooling system
}

DOI:10.36909/jer.15157

Andrés A. Sánchez-Escalona*, Yanán Camaraza-Medina**, Yoalbys Retirado-Mediaceja*, Ever Góngora-Leyva* and Manuel Vega-Almagüer***

*Faculty of Metallurgy and Electromechanical, University of Moa. 83-330 Moa, Cuba.

**Technical Sciences Faculty, University of Matanzas. 44-440, Matanzas, Cuba.

***Universidade Mandume Ya Ndemufayo, Polytechnic Higher Institute. 201, Huíla, Angola.

*Email: aescalon@ismm.edu.cu; Corresponding Author.

\begin{abstract}
Efficient utilities usage and enhanced heat transfer are imperative in todays' industrial and technological processes. However, there are several facilities in the nickel industry not upgraded yet. This research studied a hydrogen sulphide production plant with limited heat exchange capacity. Within this context, a neuro-genetic procedure was proposed for optimization of the water flowrates distribution on a hydrogen sulphide gas coolers system. It relied on Genetic Algorithms, combined with an improved $\varepsilon$-NTU model for simulation of jacketed shell-and-tube heat exchangers. Artificial Neural Networks were furtherly applied to correlate the optimum water flowrates to predictive variables. The heat transfer incremental was estimated from 3695 to $10514 \mathrm{~W}$, while reduction of the gas exit temperature was projected between 2.9 and $9.8 \mathrm{~K}$. Calculated heat recovery averaged 12.44 $\%$. The optimized water distribution scheme have improved the system energy performance. Applied concept of fixed network and unvaried overall feed water flowrate avoided the additional costs related to topology modifications. A technological solution was provided, consisting on installation of automatic valves and programmable flow control-loops linked to
\end{abstract}


a PLC.

Key words: artificial neural network; genetic algorithm; heat exchanger; heat transfer enhancement; modeling.

\section{INTRODUCTION}

This research was performed on an industrial system of jacketed shell-and-tube heat exchangers, designed to cool down the hydrogen sulphide gas from 416.15 to $310.15 \mathrm{~K}$. Despite the cooling system was devised for a heat transfer rate of $138 \mathrm{~kW}$, expected performance is currently unattained. At one hand, supplied water flowrate only represented $53.5 \%$ to $56.6 \%$ of the design value (Sánchez-Escalona et al., 2017). At the other, water flows distribution is not optimum. Since each shell have different heat loads, and water is not always the controlling thermal resistance, equal allocation of the water flowrates is unpractical from the energetic point of view. Consequently, there was a need for avoiding underutilization of the heat exchangers capacity and inefficient power usage at the water supply pumping-station.

Several researchers have studied the effect of heat exchanger connection and correct fluid placement on system effectiveness, for either stand-alone devices (Gaddis, 1986; KumarSingh, 2015; Valipour et al., 2016) or multiple shells configurations (Mukherjee, 2004; Kotiaho et al., 2015; Guo et al., 2019). However, most of the literature only refers to cocurrent and counter-current layouts, making scarce reference to the series/parallel combined arrangement. Mukherjee (2004) investigated this last scenario through a real-life refinery application (hydrocarbon liquid coolers), proposing distribution of the water flowrates to the two shells in the same ratio as their heat duties. This case was conventional, since two-fluids heat exchangers were only analyzed. A later research by Sánchez-Escalona \& Góngora-Leyva (2019) was likewise related to the series/parallel arrangement, although involving a threefluids configuration. They established a procedure for thermal analysis of the hydrogen sulphide cooling system, with the aim of improving existing facilities. In spite of the 
increased water flowrate that was recommended to reach the desired gas outlet temperature, optimization of the flows to each section of the heat exchangers was earmarked for further studies.

Another group of authors has applied optimization and heat transfer enhancement techniques to increase the equipment thermal performance (Reyes-Rodríguez \& Moya-Rodríguez, 2016; Toimil \& Gómez, 2017; Alam \& Kim, 2018; Abdul-Wahhab et al., 2021). In this ambit, when heat exchangers network (HEN) retrofit methods are implemented, two main scenarios exist: fixed network structure, and topology modification. The former is intended to maximize heat recovery by using internal fins, swirl flow devices, helical baffles, among other techniques. The second, in turn, takes full consideration of the possibilities in changing the network structure, like modification of the heat transfer area and streams repiping. Despite allowing higher water and energy savings, topology modification entails higher capital costs. Besides, it is mostly difficult at uninterrupted production plants (Akpomiemie \& Smith, 2015; Jiang et al., 2018).

Improvement of preexisting HENs have been extensively investigated (Bütün et al., 2018; Jiang et al., 2018; Biyanto et al., 2019; Klemeš et al., 2020). However, previous studies did not comprised three-fluids heat exchangers, nor optimization of the process streams flowrates as one of the heat transfer enhancement techniques that overcomes topology modifications. Taking the above into account, this paper objective was to propose a neuro-genetic procedure for optimization of the water flowrates distribution, hence increasing heat transfer across the studied system under a fixed network concept. Presented approach achieve an industrial solution that is feasible and straightforward.

\section{MATERIALS AND METHODS}

\section{System description and methodology overview}

The studied system consists of two jacketed shell-and-tube heat exchangers (three-fluid equipment), installed in a series/parallel arrangement (the hydrogen sulphide gas flows in 
series, and the water streams does in parallel). At each exchanger the gas flows on the shellside in a single pass, while the cooling water circulates at the tubeside in four passes, besides one pass thru the external jacket (Fig. 1). They operates for eight hours in gas cooling service, and later they are switched over to steam in order to remove inner sulphur buildups.

A neuro-genetic procedure was devised for optimization of the water flowrates distribution on the above-described system (Fig. 2). In brief, this improvement was performed through Genetic Algorithms (GA), using a model based on the $\varepsilon$-NTU method for simulation of the heat exchangers and calculation of the fitness function values. Then, an Artificial Neural Network (ANN) was trained and tuned-up to correlate the optimum water flowrates to the independent variables that exerts the greatest influence. Thereafter, factual heat transfer enhancement would comprise installation of automatic-actuated valves with pre-programmed control loops, loading the ANN functions on a Programmable Logic Controller (PLC).

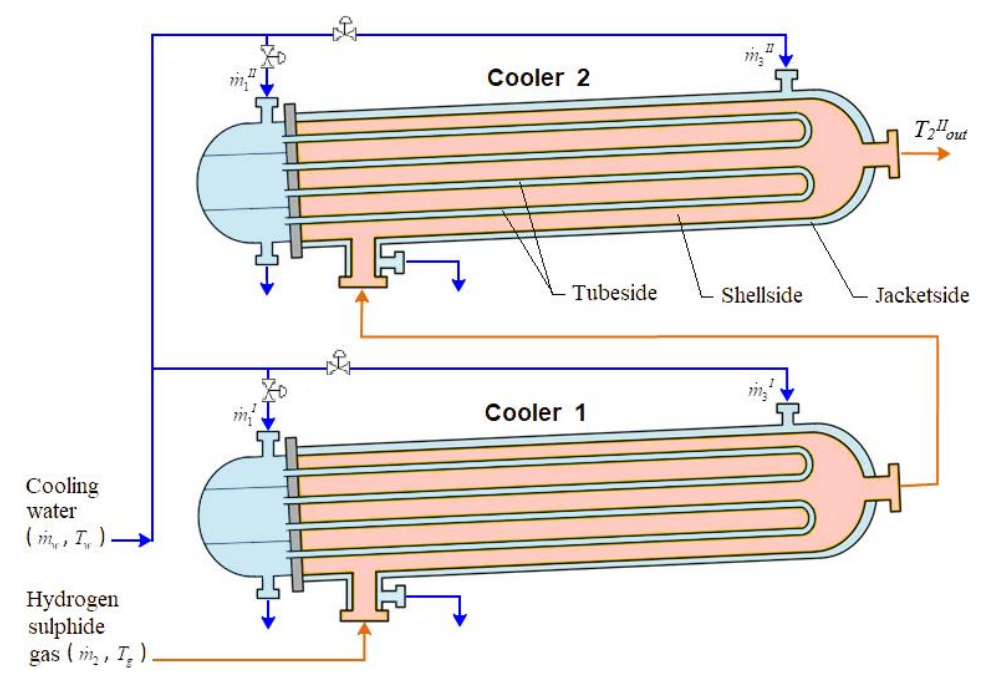

Figure 1. Hydrogen sulphide gas cooling system

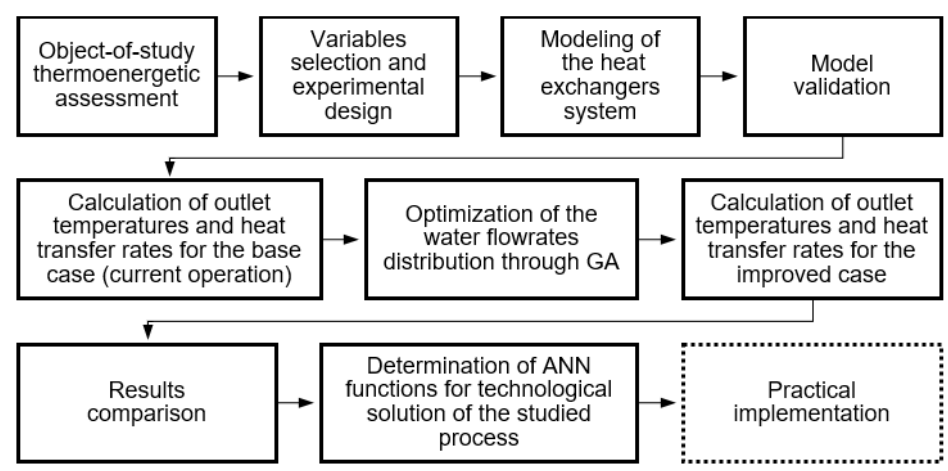


Figure 2. Applied methodology steps

\section{Variables selection and experimental design}

Selected variables matches the operational parameters having a significant effect on the studied heat transfer process. Therefore, independent variables were the inlet temperatures $\left(T_{i n}\right)$, mass flowrates $(\dot{m})$, and time $(t)$, while the dependent ones corresponded to the outlet temperatures of involved three fluids. (Sánchez-Escalona \& Góngora-Leyva, 2018).

Two independent parameters were varied when performing this research: the hydrogen sulphide mass flowrate $\left(\dot{m}_{g}\right)$, and operating time $(t)$. The remaining ones were assumed constant, since exhibited a stable trending during scheduled observations. The number of experimental runs was deduced from a $5^{2}$ full factorial design, determining each variable levels from current working regime of the object-of-study (Tab. 1) (Edmonds \& Kennedy, 2017).

Table 1. Experimental matrix for independent variables

\begin{tabular}{|c|c|c|c|c|c|}
\hline Runs & $T_{w}$ & $T_{g}$ & $\dot{\boldsymbol{m}}_{w}$ & $\dot{\boldsymbol{m}}_{g}$ & $\boldsymbol{t}$ \\
\hline \multirow{3}{*}{25} & & & & 1.0227 & 0 \\
\cline { 5 - 6 } & \multirow{3}{*}{307.45} & \multirow{3}{*}{405.83} & \multirow{3}{*}{0.82} & 1.0565 & 2 \\
\cline { 4 - 6 } & & & & 1.0903 & 4 \\
\cline { 4 - 6 } & & & & 1.1241 & 6 \\
\hline
\end{tabular}

Where: $T_{w}-$ water inlet temperature, $\mathrm{K} ; T_{g}-$ gas inlet temperature, $\mathrm{K} ; \dot{m}_{w}-$ overall feed water flowrate, $\mathrm{kg} / \mathrm{s}$. Note that $t=0$ means the system start-up time.

\section{Heat exchangers mathematical modeling}

The analytical solution proposed by Sánchez-Escalona \& Góngora-Leyva (2018) was improved and utilized herein to calculate the fluids outlet temperatures. This model, simplified through Equation (1), is based on the heat transfer rate equation, the overall energy balance, as well as the expressions derived from the $\varepsilon$-NTU method that pertains to threefluids heat exchangers with two major thermal communications. Single-phase steady flows, 
constant fluids thermo-physical properties, plus no heat losses to the surroundings were assumed.

$$
\left\{T_{1 \text { out }}, T_{2 \text { out }}, T_{3 \text { out }}, Q\right\}=f\left(T_{g}, T_{w}, \dot{m}_{1}, \dot{m}_{g}, \dot{m}_{3}, t \text {, fluids properties }\right)
$$

Where: $T_{1 \text { out }}-$ tubeside water outlet temperature, $\mathrm{K} ; T_{2 \text { out }}-$ gas outlet temperature, $\mathrm{K}$; $T_{3 \text { out }}-$ jacketside water outlet temperature, $\mathrm{K} ; Q$ - heat transfer rate throughout the heat exchanger, $\mathrm{W} ; \dot{m}_{1}$ - tubeside water mass flowrate, $\mathrm{kg} / \mathrm{s} ; \dot{m}_{3}$ - jacketside water mass flowrate, $\mathrm{kg} / \mathrm{s}$. On the studied case $T_{2 \text { in }}=T_{g}$, and $T_{1 \text { in }}=T_{3 \text { in }}=T_{w}$.

In order to validate current model, three experimental observations were carried out on alternate days, during eight hours of operation. On each cycle, twenty measurements of the mass flowrates, inlet and outlet temperatures were recorded for every stream, on each cooler, hence obtaining a 120 rows database. Predictions were compared to measured outlet temperatures

( $T_{1 \text { out }}, T_{2 \text { out }}$ and $T_{3 \text { out }}$ ) to confirm the outputs accuracy (Ali, 2021a; Usman et al., 2021).

\section{Optimization algorithm}

Utilized optimization method was GA. This stochastic iterative search technique is inspired by the principles of natural selection, with optimization strategies that are grounded on basic operators like selection, crossover and mutation (Moslemi \& Keshtkar, 2018). On this research, GA functions were developed and configured in MATLAB®. The logical sequence that was applied is synthesized on next graph (Fig. 3). 


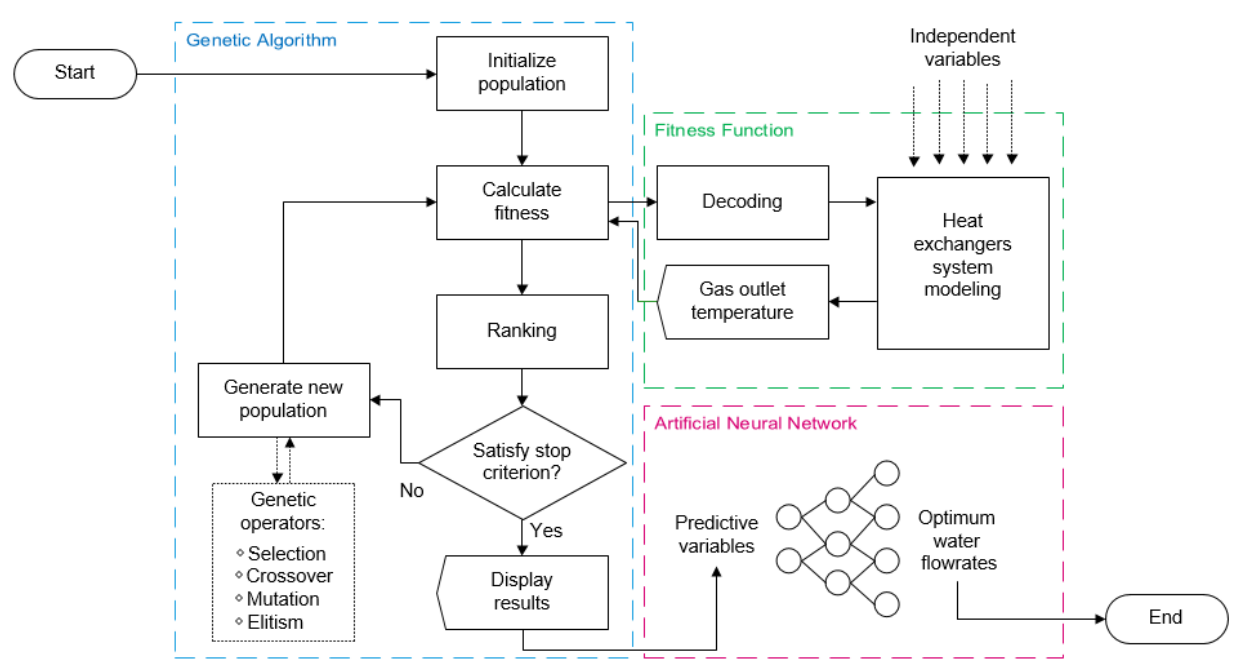

Figure 3. Neuro-genetic procedure flowchart

The fitness function consisted of the gas outlet temperature at the second cooler $\left(T_{2}^{I I}\right.$ out $)$. The decoding module, which uses the GA variables $\left(X_{1}, X_{2}\right.$ and $\left.X_{3}\right)$ to establish the water flowrates to each section of the heat exchangers, relied on expressions from Equation (2) to Equation (5).

Water flowrates distribution on cooler 1 (stage I):

$\dot{m}_{1}^{I}=X_{1} \cdot X_{2} \cdot \dot{m}_{w}$

$\dot{m}_{3}{ }^{I}=X_{1} \cdot\left(1-X_{2}\right) \cdot \dot{m}_{w}$

Water flowrates distribution on cooler 2 (stage II):

$\dot{m}_{1}^{I I}=\left(1-X_{1}\right) \cdot X_{3} \cdot \dot{m}_{w}$

$\dot{m}_{3}^{I I}=\left(1-X_{1}\right) \cdot\left(1-X_{3}\right) \cdot \dot{m}_{w}$

In previous equations $X_{k} \in(0,1) \mid \forall k \in\{1,2,3\}$. Superscripts $I$ and $I I$ denotes the first and second cooling stages. Parameter $X_{1}$ is the fraction from the overall water flowrate that is pumped to the first cooler, being $1-X_{1}$ the balance to the second one. $X_{2}$ describes the ratio of the water flowrate going to the first cooler that flows through the tubeside, while $1-X_{2}$ means the rest, flowing across the first jacket. Analogously, $X_{3}$ defines the ratio of the water flowrate on the second cooler that goes through its tubeside, and $1-X_{3}$ means the remaining fraction that reaches the second jacket. For the base case (current operation of the studied 
system) it was experimentally corroborated that $X_{1}=0.500$ and $X_{2}=X_{3}=0.723$, with uniform trending.

\section{ANN functions}

ANN functions were envisioned for technological solution of the studied problem. Hence, this artificial intelligence tool was applied for accurate correlation of selected predictive and response variables, as symbolized by Equation (6):

$$
\left\{\dot{m}_{1}^{I}, \dot{m}_{3}{ }^{I}, \dot{m}_{1}^{I I}, \dot{m}_{3}{ }^{I I}\right\}=f\left(\dot{m}_{g}, t\right)
$$

The network architecture comprised a multilayer feed forward network (multilayer perceptron). The number of neurons in the input and output layers matched the number of independent and dependent variables, respectively, whilst hidden layers and hidden neurons were optimized by means of a network growing strategy. The log-sigmoid transfer function (logsig) was used in the hidden layer, while the linear transfer function (purelin) was employed in the output one. Network training, validation and testing were carried out by using the data points from the $5^{2}$ full factorial design, complemented with the optimization process results. The Bayesian Regularization algorithm (trainbr) was used for training (Beale et al., 2017).

\section{RESULTS AND DISCUSSION \\ Modeling and optimization results}

Accuracy of the analytical model that was used to simulate the heat exchangers thermal performance ensured reliability of the results. It was confirmed by comparing predicted values with measured outlet temperatures, which lead to very low error indexes and strong linear association degrees between the dependent variables (Tab. 2).

Table 2. Accuracy of the heat exchangers model

\begin{tabular}{|l|c|c|c|c|}
\hline Output variable & $\boldsymbol{R}^{\mathbf{2}}$ & $\boldsymbol{R}$ & $\boldsymbol{e}_{\text {ave }}$ & $\boldsymbol{e}_{\max }$ \\
\hline$T_{1 \text { out }}$ & $90.2 \%$ & $95.0 \%$ & $0.34 \%$ & $2.03 \%$ \\
\hline$T_{2 \text { out }}$ & $94.3 \%$ & $97.1 \%$ & $0.76 \%$ & $4.10 \%$ \\
\hline$T_{3 \text { out }}$ & $91.2 \%$ & $95.5 \%$ & $0.33 \%$ & $1.36 \%$ \\
\hline
\end{tabular}


Where: $R^{2}$ - determination coefficient; $R$ - Pearson correlation coefficient; $e_{\text {ave }}-$ absolute percentage error; $e_{\max }-$ maximum absolute percentage error.

Main results for the base case and the improved scenario were computed as function of the hydrogen sulphide mass flowrate and operating time. While the baseline exhibited fixed water flows distribution ( $X_{1}, X_{2}$ and $X_{3}$ are constant), the optimized case disclosed changeable water flowrates $\left(X_{1}, X_{2}\right.$ and $X_{3}$ vary as function of $\dot{m}_{g}$ and $\left.t\right)$.

\section{Base case versus improved case: theoretical discussion}

Operation with water flowrates that are fixed, as well as balanced to every cooling stage, restrain higher thermal efficiency levels. Since both heat exchangers are of the same size and capacity, the hotter shell delivers a greater heat duty as compared to the colder one, mainly by virtue of a higher mean temperature difference (Mukherjee, 2004; Sánchez-Escalona et al., 2017). It not only causes a heat transfer surplus to the first-stage water streams, but also a thermal capacitance underutilization for the second-stage cooling water. Given that cooling water is not the controlling fluid, any flow in excess will only have a discreet influence on the overall heat transfer coefficients and, consequently, a lower impact on total heat transfer rate. The optimum heat transfer rates are linked to variable water flows distribution, which essentially depend upon the hydrogen sulphide production target and elapsed time (Fig. 4). This fact is also attributable to heat exchangers with several thermal communications, since the best possible effectiveness is achieved when the sum of individual heat transfer rates reaches the maximum. Under such circumstances, the water streams can be coordinately split to the different sections of the heat exchangers, providing the lower thermal-resistance communications with higher water flowrates. The shellside fluid and fouling rates defines the controlling thermal resistance, therefore they drives distribution of the water flowrates. 


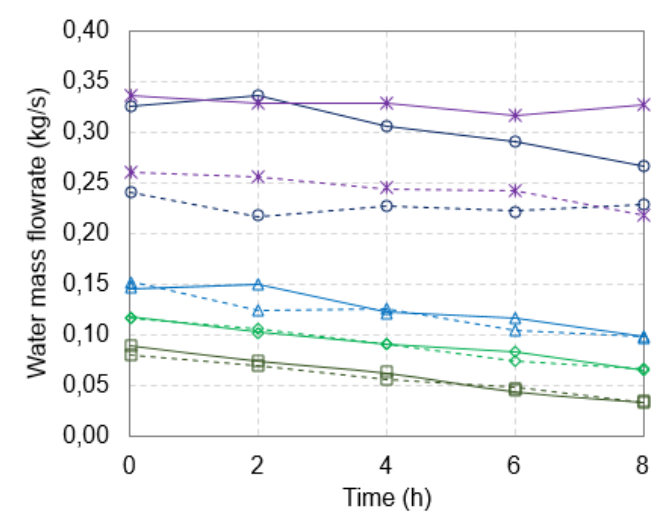

a) Tubeside water

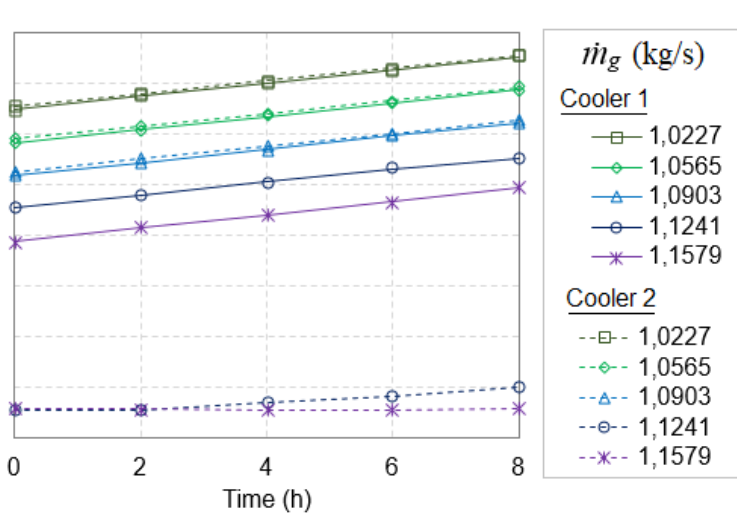

b) Jacketside water

Figure 4. Optimized water flowrates distribution

In general terms, the water flowrate fraction increases at the tubeside with a rise on the hydrogen sulphide flow, while declines with the incremental of time (Fig. 4a). On the former scenario, higher gas flowrates are related to lower thermal resistances of the boundary layers at the shellside-to-tubeside thermal communication, as well as lower scale buildups over the tube bundle. Hence, as previously mentioned, the lower-resistance thermal communications are provided with higher water flowrates. On the second situation, despite the progression of time causes greater fouling levels around all existing heat transfer surfaces, depositions over the heat exchanger tubes (shellside-to-tubeside thermal communication) occurs faster as compared to buildups over the shell cylindrical plate (shellside-to-jacketside thermal communication). Therefore, the thermal resistance decreases on the second thermal communication, entailing more water to the jacket for improved system performance.

Conversely, the water flowrate fraction decreases through the jacketside with a rise on the hydrogen sulphide stream, while augmenting with the incremental of time (Fig. 4b). Physical insights are alike the ones explained on previous paragraph. On the other hand, despite the water flows distribution is fairly similar between cooler 1 and cooler 2 at hydrogen sulphide flowrates up to $1.0903 \mathrm{~kg} / \mathrm{s}$, larger differences are noticed for 1.1241 and $1.1579 \mathrm{~kg} / \mathrm{s}$. Since the streams heat capacity rates gets closer at the greater gas flows, the water is prioritized to the first cooling stage for taking advantage of a broader mean temperature difference. 


\section{Base case versus improved case: quantitative comparison}

Proposed optimization scheme would allow a heat transfer incremental from 3695 to 10514 $\mathrm{W}$, as well as a gas temperature reduction at the outlet of the cooling system that varies from 2.9 to $9.8 \mathrm{~K}$ (Fig. 5). This fact would favor a rational water consumption, as well as a more effective usage of the pumping power, thus an efficient use of the electric power.
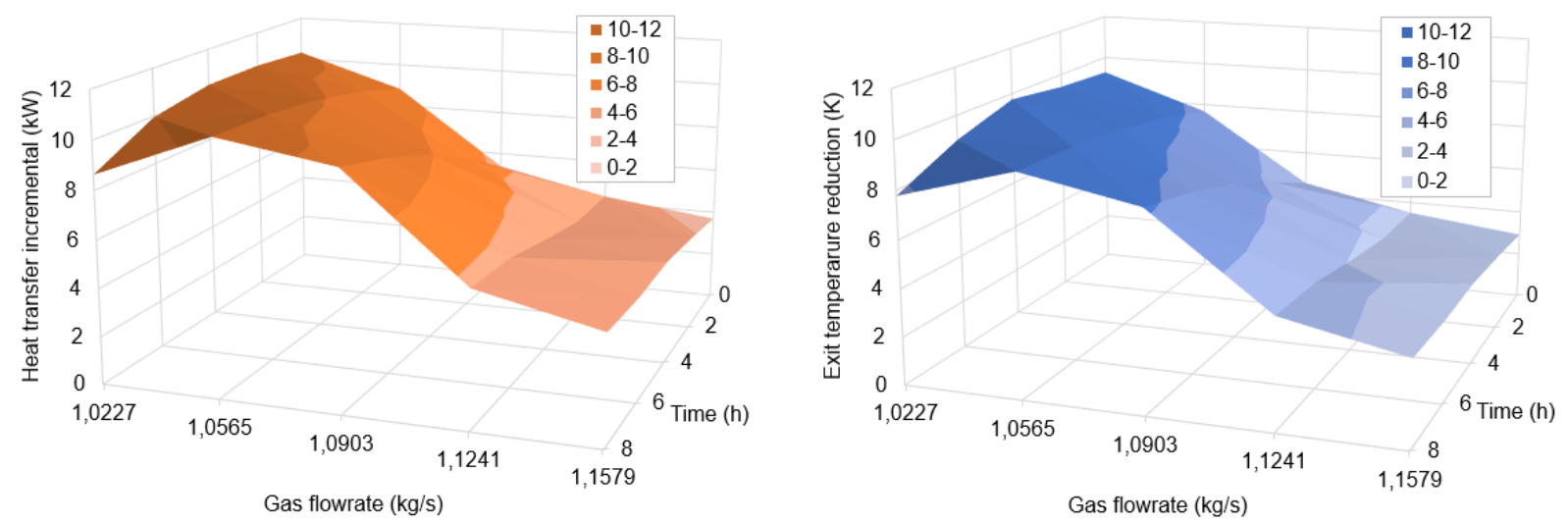

Figure 5. Improved case benefits

According to Jiang et al. (2018), when applying existing enhancement techniques under a fixed network approach (such as internal fin, twisted tape insert, helical baffle, etc.), heat recovery for the retrofitted HEN can be increased by up to $7.69 \%$. Zhang et al. (2018) reported an improved heat transfer efficiency that exceeds $12 \%$, as compared to the nonoptimized heat exchangers, by applying a combination of heat transfer enhancement techniques that relied on fins and special geometry. Moreover, Čuček et al. (2019) and Wang et al. (2019) informed energy savings for industrial plants and sites from 5 to $35 \%$. Comparable heat recovery levels were determined in present work, averaging $12.44 \%$ and varying from 3.90 to $22.16 \%$.

There are other cooling techniques with phase-change materials, nanofluids and their combined use, which lead to efficiency enhancement of the system. For instance, maximum incremental of $20 \%$ in PV-efficiency is reported for the passive cooling approach with phase change materials (Ali, 2020). Besides, temperature reductions from 29.53 to $42.81 \%$ were determined for heat sink aided with nanoparticle-enhanced phase change material and heat 
pipe, for the passive cooling of electronic components (Ali, 2021b). In present work, temperature reductions in main process stream averaged $1.79 \%$, varying from 0.88 to a maximum of $2.68 \%$.

\section{Technological solution for the studied problem}

Optimum water flowrates to each section of the heat exchangers were correlated to the hydrogen sulphide mass flowrate and operating time, by means of a general regression ANN model. The network structure consisted on a 2-2-4 multilayer perceptron. Computed weights and biases (Fig. 6) provided a strong $100 \%$ correlation, besides average and maximum absolute percentage errors of $7.80 \cdot 10^{-6}$ and $2.86 \cdot 10^{-5} \%$, respectively.

$$
w_{m 1}=\left[\begin{array}{rr}
-0.2150 & -0.0923 \\
0.2149 & 0.0922
\end{array}\right] \cdot 10^{-3} \quad b_{1}=\left[\begin{array}{l}
0.0112 \\
0.0112
\end{array}\right] \quad w_{m 2}=\left[\begin{array}{ll}
0.0988 & 0.0991 \\
0.0377 & 0.0381 \\
0.0992 & 0.0988 \\
0.0381 & 0.0378
\end{array}\right] \quad b_{2}=\left[\begin{array}{l}
0.1969 \\
0.0754 \\
0.1969 \\
0.0754
\end{array}\right]
$$

Figure 6. ANN weights and biases values

Automatic valves together with flow control closed-loops were proposed for installation on each water pipe feeding the heat exchangers. Determined ANN functions, which controls valves opening, are downloaded into a Siemens S7-400 programmable logic controller (PLC). The Simulink PLC Coder, included in MATLAB®, can be utilized for ANN programming. It generates hardware-independent structured text from Simulink® models, Stateflow ${ }^{\circledR}$ charts and integrated functions, according to the IEC 61131-3 standard. The structured text can be generated in SIMATIC STEP 7, whose file formats are supported by integrated development environments (IDE). By doing the above, the application is compiled and deployed on the PLC. It is also necessary to define the network structure and the system to be controlled, i.e. multiple-inputs multiple-outputs (MIMO). The inputs, outputs, and controller type are set afterwards. Once the model definition is complete, the data is uploaded to the PLC and the SCADA system. During the operation, the PLC uses the predictive variables to generate the best possible response for chosen output parameters (Saleh \& Mosa, 2016). 


\section{CONCLUSIONS}

This work contributed to the upgrade of an industrial process. An improved water distribution scheme was proposed for the hydrogen sulphide gas coolers, increasing its energy performance under a fixed network concept. Optimum heat transfer rates were related to variable water flows to the heat exchangers sections, determined as a function of gas flowrate and operating time.

Heat transfer incremental varied from 3695 to $10514 \mathrm{~W}$, while the gas temperature reduction at the system outlet fluctuated from 2.9 to $9.8 \mathrm{~K}$. Calculated heat recovery averaged $12.44 \%$, moving from 3.90 to $22.16 \%$. Provided technological solution is practical in design, costeffective, and environment friendly, allowing its further implementation in similar facilities.

Future studies should review the effect of overall feed water flowrates different from 0.82 $\mathrm{kg} / \mathrm{s}$, plus the influence of additional independent variables like fluid inlet temperatures.

\section{REFERENCES}

Abdul-Wahhab, H. A.; Aljabair, S. \& Ayed, S. K. 2021. Assessment of wind fin performance run by mixed flows: experimental and numerical investigations. Arabian Journal for Science and Engineering (2021). https://doi.org/10.1007/s13369-021-05843-w

Ali, H. M. 2020. Recent advancements in PV cooling and efficiency enhancement integrating phase change materials based systems - A comprehensive review. Solar Energy 197(-): 163-198. https://doi.org/10.1016/j.solener.2019.11.075

Ali, H. M. 2021a. A semi-empirical model for retained condensate on horizontal pin-fin tube including the effect of vapour velocity. Case Studies in Thermal Engineering 28(-): 101420. https://doi.org/10.1016/j.csite.2021.101420

Ali, H. M. 2021b. Analysis of heat pipe-aided graphene-oxide passed nanoparticle-enhanced phase change material heat sink for passive cooling of electronic components. Journal of Thermal Analysis and Calorimetry 146(-): 277-286. https://doi.org/10.1007/s10973-02009946-8. 
Akpomiemie, M. O. \& Smith, R. 2015. Retrofit of heat exchanger networks without topology modifications and additional heat transfer area. Applied Energy 159(-): 381-390. http://dx.doi.org/10.1016/j.apenergy.2015.09.017

Alam, T. \& Kim, M-H. 2018. A comprehensive review on single phase heat transfer enhancement techniques in heat exchangers applications. Renewable and Sustainable energy Reviews 81(-): 813-839. http://dx.doi.org/10.1016/j.rser.2017.08.060

Beale, M. H.; Hagan, M. T. \& Demuth, H. B. 2017. Neural Network Toolbox ${ }^{\mathrm{TM}}$ User's Guide. The MathWorks Inc., Massachusetts.

Biyanto, T. R.; Tama, N. E.; Permatasari, I.; Sabillah, M. G.; Napitupulu, D. H. \& Anda, A. R. 2019. Optimization heat transfer coefficient in retrofit heat exchanger network using Pinch Analysis and Killer Whale Algorithm. AIP Conference Proceedings, 2088-020051. https://doi.org/10.1063/1.5095303

Bütün, H.; Kantor, I.; Mian, A. \& Maréchal, F. 2018. A heat load method for retrofitting heat exchanger networks. 28th European Symposium on Computed Aided Process Engineering. Graz, Austria. https://doi.org/10.1016/B978-0-444-64235-6.50244-8

Čuček, L.; Boldyryev, S.; Klemeš, J. J.; Kravanja, Z.; Krajačić, G.; Varbanov, P. S. \& Duić, N. 2019. Approaches for retrofitting heat exchanger networks within processes and Total Sites. Journal of Cleaner Production 211(-): 884-894. https://doi.org/10.1016/ j.jclepro.2018.11.129.

Edmonds, W. A. \& Kennedy, T. D. 2017. An applied guide to research designs: quantitative, qualitative, and mixed methods, 2nd ed. SAGE Publications, Los Angeles.

Gaddis E. S., 1986. Shell and tube heat exchangers with segmental baffles. In: Heat Exchanger Design Handbook. Hemisphere Publishing, London.

Guo, J.; Cui, X.; Huai, X.; Cheng, K. \& Zhang, H. 2019. The coordination distribution analysis on the series schemes of heat exchanger system. International Journal of Heat and Mass Transfer 129(-): 37-46. https://doi.org/10.1016/j.ijheatmasstransfer.2018.09.068 
Jiang, N.; Han, W.; Guo, F.; Yu, H.; Xu, Y. \& Mao, N. 2018. A novel heat exchanger network retrofit approach based on performance reassessment. Energy Conversion and Management 177(-): 477-492. https://doi.org/10.1016/j.econman.2018.10.001

Klemeš, J. J.; Wang, Q-W.; Varbanov, P. S.; Zeng, M.; Chin, H. H.; Lal, N. S.; Li, N-Q.; Wang, B.; Wang, X-C. \& Walmsley, T. G. 2020. Heat transfer enhancement, intensification and optimization in heat exchanger network retrofit and operation. Renewable and Sustainable Energy Reviews 120: 109644. https://doi.org/10.1016/j.rser.2019.109644

Kotiaho, V. W.; Lampinen, M. J. \& Assad, E. H. 2015. Effect of heat exchanger connection on effectiveness. Journal of Robotics and Mechanical Engineering Research 1(1): 11-17. http://www.verizonaonlinepublishing.com

Kumar-Singh, S. 2015. Thermal design guidelines for optimizing shell-and-tube heat exchangers. Chemical Engineering 122(2): 54-57.

Moslemi, H. R. \& Keshtkar, M. M. 2018. Sensitivity analysis and thermal performance of evacuated U-tube solar collector using genetic algorithm. International Journal of Heat and Technology 36(4): 1193-1202. https://doi.org/10.18280/ijht.360406

Mukherjee, E. 2004. Practical Thermal Design of Shell-and-Tube Heat Exchangers. Begell House, New York.

Reyes-Rodríguez, M. B. \& Moya-Rodríguez, J. L. 2016. Design and optimization of shell and tube heat exchangers, state of the art. Journal of Engineering and Technology for Industrial Applications 2(6): 4-27. https://dx.doi.org/10.5935/2447-0228.20160011

Saleh, A. \& Mosa, M. 2016. Analysis of control strategies and simulation of heating systems using Simulink/Matlab potential. Journal of Thermal Engineering 2(5): 921-927. https://doi.org/10.18186/jte.97874

Sánchez-Escalona, A. A.; Góngora-Leyva, E.; Zalazar-Oliva, C. \& Álvarez-Hernández, E. 2017. Análisis del intercambio de calor e incrustaciones en un sistema de enfriadores de ácido sulfhídrico. Minería \& Geología 33(3): 326-340. 
Sánchez-Escalona, A. A. \& Góngora-Leyva, E. 2018. Artificial neural network modeling of hydrogen sulphide gas coolers ensuring extrapolation capability. Mathematical Modelling of Engineering Problems 5(4): 348-356. https://doi.org/10.18280/mmep.050411

Sánchez-Escalona, A. A. \& Góngora-Leyva, E. 2019. Improvements to the Heat Transfer Process on a Hydrogen Sulphide Gas Coolers System. International Journal of Heat and Technology 37(1): 249-256. https://doi.org/10.18280/ ijht.370130

Toimil, D. \& Gómez, A. 2017. Review of metaheuristics applied to heat exchanger network design. Transactions in Operational Research 24(-): 7-26. https://doi.org/10.1111/itor.12296

Usman, M.; Ali, M.; Rashid, T.; Ali, H. M. \& Frey, G. 2021. Towards zero energy solar households - A model-based simulation and optimization analysis for a humid subtropical climate. Sustainable Energy Technologies and Assessments 48(-): 101574. https://doi.org/ 10.1016/j.seta.2021.101574

Valipour, P.; Ghasemi, S. E.; Khosravani, M. R. \& Ganji, D. D. 2016. Theoretical analysis on nonlinear vibration of fluid flow in single-walled carbon nanotube. Journal of Theoretical and Applied Physics 10(-): 211-218. https://doi.org/10.1007/s40094-016-02179

Wang, C.; Guang, C.; Zhang, Z. S. \& Gao, J. 2019. Design and optimization of heat exchange network and exergy analysis for methanation process of coal gas. Latin American Applied Research 49(1): 47-54. https://doi.org/10.52292/j.laar.2019.284

Zhang, P.; Ma, T.; Li, W-D.; Ma, G-Y. \& Wang, Q-W. 2018. Design and optimization of a novel high temperature heat exchanger for waste heat cascade recovery from exhaust flue gases. Energy 160(-): 3-18. https://doi.org/10.1016/j.energy.2018.06.216 